\title{
Contribution of the study of the properties of carbenes with advanced quantum chemistry calculations: geometries
}

\author{
L. L. Alao; L.A. Bede; M. Koné; B. A. Assoma; Y. T. N'guessan* \\ Laboratoire de Chimie Organique Structurale: UFR-SSMT Université de Cocody; \\ 22 BP 582 Abidjan 22 (Côte-d'Ivoire)
}

\begin{abstract}
The purpose of this work is to determine the geometric parameters of methylene and six (6) analogues in the first electronic states: singlet state (SO) and triplet state (T1) with advanced quantum chemistry methods for a better knowledge of their structures. For this reason, we used Hartree-Fock (HF), MP2, B3LYP, G3, CBS - Q and CBS APNO levels of theory associated with correlated Dunning basis set (cc-pVTZ), using the Gaussian 03 suite of programs.

According to this study, we observe that $\mathrm{C}-\mathrm{H}$ bond lengths are always larger in the So state than in the T1 state for the methylene; according to the results of all computational methods used. For $\mathrm{C}-\mathrm{X}(\mathrm{X}=\mathrm{Cl})$ bond, we have the same behavior as for $\mathrm{C}-\mathrm{H}$ bond in the methylene. When $\mathrm{X}$ $=\mathrm{F}$, we have an opposite behavior. Indeed, $\mathrm{C}-\mathrm{X}$ bond is always longer in the state $\mathrm{T} 1$ than in the state SO. Concerning bond angles, we observe that, the angle XCY is always smaller $\left(100^{\circ}\right.$ $\left.110^{\circ}\right)$ in the So state than the $\mathrm{T} 1$ one $\left(118^{\circ}-135^{\circ}\right)$. The valence angle increases from $\mathrm{F}$ to $\mathrm{Cl}$; this may be explained both by the decrease of electronegativity and the steric hindrance of atoms becoming increasingly large. In the particular case of the monohydroxycarbene and dihydroxycarbene, we have a slightly more complex geometry than methylene and group of the halogenocarbenes because here, a dihedral angle is in addition to other internal drawcords.
\end{abstract}

Keywords: carbene;.metylene; state S0; state T1; Hartree-Fock; bond length, dihedral angle.

\section{INTRODUCTION}

The carbenes are divalent carbon chemical species; they belong to the family of compounds that have a very short life. These compounds have often been studied by generations of scientists since the advent of chemistry in the 19th century (ref, 1897).

The carbenes can be obtained by photolysis of "diazo" or "DIAZIRIN" (Figure 1)

They are intermediaries in several reactions. They are very reactive organic entities not detectable (except in the form of the ligand in metal complexes) and are also unstable because of their two electrons not involved in bonds.

These two electrons allow to distinguish three electronic states of carbenes: fundamental Singlet state S0 (the two uncommitted electrons spin occupy the same molecular orbital and are paired), excited state S1 (the two different uncommitted electrons spin are located in different orbitals) and excited state T1 (the two same uncommitted electrons are located in different orbitals). (Figure 2)
In our laboratory, a previous work was devoted to the theoretical studies on the structure and reactivity of carbenes with semi empirical methods (AM1 and MNDO) by Dr. ADEOTI (1998). In the present work, we extend our investigation with more sophisticated quantum chemical methods such as: ab-initio Hartree-Fock (Roothaan, 1951), (Hehre, W.J., Radom, L., Schleyer, P.v.R., and Pople, J.A., 1986) (MP2) composed methods (G3, CBS - Q, and CBS APNO) (Curtiss et al., 1998), (Cossi et al., 2001), (Foresman et al., 1996), (Knowless et al., 2000), (Curtiss et al.,1998), (Petersson et al., 1991) and DFT (B3LYP) (Hohenberg al.., 1964) KONH et al. (1965) levels of theory for a better description of their geometry (Szabo, A., Ostlung, 1989). We build on the earlier studies of geometry of carbenes calculated by Dr Adéoti. The study investigated in total seven (7) compounds: methylene, two hydrohalogenocarbenes (hydrofluorocarbene, hydrochlorocarbene), the monohydroxycarbene, two (2) dihalogenocarbenes (difluorocarbene, dichlorocarbene) and the dihydroxycarbene.

Computational methods of calculations: The nature of the molecules studied and their size allows 
us to use very specific ways, for a better determination of their structures. Therefore, in addition to the ab-initio methods (Hartree - Fock ) levels of theory, we used density functional theory (B3LYP) and composed-methods theory (G3, CBS $\mathrm{Q}$, CBS-APNO). All geometries and frequencies calculations were carried out using the Gaussian 03 suite of program (Frish et al., 2003). The geometries of the seven (7) carbenes studied were fully optimized at B3LYP, MP2, G3, CBS - Q, and CBSAPNO levels of theory using when it was necessary cc-pVTZ basis set. The use of Dunning basis set (ccpVTZ) was justified by the fact that it is already correlated, that improve the correlation of electrons. In this basis set, the number of orbital for $\mathrm{H}$ are $3 \mathrm{~s}$, $2 p, 1 d$ (14 functions); 4s, 3p, 2d 1f (30 functions) for $\mathrm{C}, \mathrm{O}$, and $\mathrm{F} ; 5 \mathrm{~s} 4 \mathrm{p} 2 \mathrm{~d} 1 \mathrm{f}$ (34 functions) for $\mathrm{Cl}$.

All stationary points were confirmed as true minima and all transition points were confirmed too by one imaginary frequency via vibrational frequency calculation.

The use of these sophisticated methods associated with mentioned basis set will contributes to obtain good parameters for a better description of the studied carbenes.

\section{RESULTS AND DISCUSSION}

Presentation of studied compounds: Below, we represent molecules undergo our study (figure 3).

The methylene ( $\mathbf{C H} 2)$, presents a tetravalent carbon associated with two hydrogen atoms. Two of the four valence electrons are not engaged in a bond. Substitution of a methylene hydrogen by one $\mathrm{OH}$ or a halogen $(\mathrm{X}=\mathrm{F}, \mathrm{Cl})$, leads to a monosubstituted carbene; the monohydroxycarbene and hydrohalogenocarbenes respectively. When the two hydrogens are substituted by two $\mathrm{OH}$ or two halogens $(\mathrm{X}=\mathrm{F}, \mathrm{Cl})$, we obtain respectively the dihydroxycarbene and dihalogenocarbenes.

\section{Geometry}

\section{Methylene}

Bond length: In methylene, $\mathrm{C}-\mathrm{H}$ bond in state $\mathrm{SO}$ is always longer than in state $\mathrm{T} 1$ regardless of all the methods used (table 1 and Graphic.1). In table 1 we note that in going from state $\mathrm{T} 1$ to state S0, the average values of the difference of $\mathrm{C}-\mathrm{H}$ length of the two states is about $0.030 \AA$, which is consistent with results of Balázs and Coll (2000). Indeed the difference found between $\mathrm{C}-\mathrm{H}$ length of the state $\mathrm{SO}$ and state $\mathrm{T} 1$ by this author is $0.033 \AA$ (Balázs and al., 2000). In this table we notice also that the T1 length is on average equal to $1.1 \AA$, this also is consistent with the experimental value of 1.07 found by R.W.ALDER et al. (1982). Data from the literature give $1.11 \AA$ for $\mathrm{C}-\mathrm{H}$ bond length of $\mathrm{S} 0$ methylene (Herzberg, 1972, 1974 ;) Zittel and al. (1976) and the T1 methylene one between 1,075 and 1,085 $\AA$ (Herzberg, 1972 ;) Zittel et al. 1976; Herzberg and Johns, 1971; Sears et al. 1980; Jensen et al. (1982) are also in agreement with our calculations.

Bond Angle: Bond angle was always higher in state T1 than in state S0 regardless of the quantum chemical methods employed (table 2 and Figure 2). This result is confirmed by Joel Liebman and Jack Simons F (1986). Indeed these authors found the $\mathrm{HCH}$ angle in methylene singlet smaller than in methylene triplet (Joel F. Liebman and Jack Simons, 1986). Our calculations were also adequate with those of Balázs et al. (2000), these authors found that the $\mathrm{HCH}$ angle of methylene singlet is $101.5^{\circ}$ and the triplet one $133,1^{\circ}$ (R.W.ALDER et al., 1982).

In state S0, the $102^{\circ}$ values of the bond angle look like a $\mathrm{sp}^{3}$ hybridization of carbon, in accordance with the work of ADEOTI (1998).

In the electronic structure of methylene, two atoms of hydrogen-related carbon leaves one of the two $p$ orbitals empty; so, the carbon atom have a lone pair. This lone pair creates in the immediate vicinity of the atom that bears it, a charge density higher than a doublet embarked upon a bond.

This creates repulsion forces. These lead to the decline of the bond angle which is smaller than that contemplated by $\mathrm{sp}^{3}$ hybridization (ADEOTI, 1998). The results obtained by our calculations in Hartree Fock level of theory are consistent with this observation as well as those made by MP2 level of theory in a minimal basis set by Karl (1992), this author found $104,8^{\circ}$ like the value of the angle. In state $T 1$, the bond angle is around $135^{\circ}$, this value is between $\mathrm{sp}^{2}$ hybridization and $\mathrm{sp}$ hybridization. We know that hybridization $\mathrm{sp}^{3}$ bond length is greater than that of $\mathrm{sp}^{2}$ itself superior to $\mathrm{sp}$ hybridization. At the bond angle, it moves in the opposite direction $\left(\alpha_{s p}>\alpha_{s p 2}>\alpha_{s p 3}\right)$.This is confirmed by the

electronic states of methylene (figure 4).

The results of our calculations were confirmed by the $103^{\circ}$ value of the $\mathrm{HCH}$ angle for Singlet (Bauschlicher and al., 1977) and $136^{\circ}$ for the triplet (Wasserman and al. 1971) obtained by the HÜCKEL 
method (Jensen P and Bunker P.R, 1988;) Bauschlicher et al. 1977;Wasserman and al. (1971) and by the literature values, where the bond angle $\mathrm{HCH}$ of methylene S0 is between $102^{\circ}$ and $104^{\circ}$ [11-(Herzberg,_1972,1974)] Zittel and al. (1976). The values of Methylene T1 one are between $133.9^{\circ}$ and $136^{\circ}$ (Herzberg, 1972;), Zittel and al. 1976; Herzberg and Johns, 1971; Sears and al. 1980; Jensen and al. (1982). These observations are both explained by the effect of electron repulsion and by the effect of hybridization.

\section{Hydrohalogenocarbenes}

\section{bond Length}

C-X Length : The values of $C-X$ bond of the hydrohalogenocarbene are almost the same in the S0 state and in the T1 state (table 3 and graph 2) whatever the halogen and the calculation method used, but they grow inside the S0 state and the T1 state from fluoride to chlorine, i.e. from the substituent more electronegative to the substituent less electronegative

C-H Length: $\mathrm{C} \mathrm{-} \mathrm{H}$ bond length is always longer in the S0 state than the state $\mathrm{T} 1$ as observed in the methylene, (table 4, graphic 3). It decreases from chlorine to fluorine i.e., from the more electronegative substituent to the lest one's. This can be explained by the strong electronegativity of fluorine which attracts more to him the doublet of link, shortening the $\mathrm{C}-\mathrm{H}$ bond. Inside the T1 state, bond length varies very little regardless of the hydrohalogenocarbene.

Bond Angle: $\mathrm{H}-\mathrm{C}-\mathrm{X}$ bond angles are larger at the $\mathrm{T} 1$ state than at the SO state, regardless of the hydrohalogenocarbenes and the calculation method used, (table 5 and graphic 4) as for the methylene. At the T1 state, we observe the slight increase of the bond length from the more electronegative substituent to the least electronegative ones. CHF angle is smaller because of a strong attraction between the atom of hydrogen and the atom of fluorine. The Lowest attraction with the chlorine then gives a larger bond angle with fluorine. At the S0 state, the bond angle is virtually identical everywhere. These observations on the $\mathrm{X}-\mathrm{C}-\mathrm{H}$ bond angle obtained by our calculations were confirmed by Karl et al. (1992), by the results of the calculations in CCSD (T) / 6-311 ++ G (d, p) level of theory ( Balázs et al. (2000)), and as well as by the experimental results available in the literature (Herzberg, 1972;) Merer and Travis, 1966; Jacox and Milligan, 1967, 1969, 1970; Samsonov and Petrov, 1981; Kakimoto and al. 1981, 1983, 1990; Goldfield and Simon, 1961; (Dixon and Simon, 1970).

In fact these authors found $\mathrm{H}-\mathrm{C}-\mathrm{X}$ bond angle at the S0 state smaller than to T1 state for those studied hydrohalogenocarbenes. They found that the bond angle increases to fluorine to chlorine too.

We can say that $\mathrm{X}-\mathrm{C}-\mathrm{H}$ bond angles are always larger in the $\mathrm{T} 1$ triplet sate than in $\mathrm{S} 0$ singlet state.

Monohydroxycarbene: We study two electronic states of monohydroxymethylene with the methods used. Optimized geometries in both electronic states are shown in figure 5 .

For the monohydroxycarbenes, the geometry is slightly more complex than the geometry of previous studied carbenes. Indeed, in addition to lengths and bond angles, we also have the presence of a dihedral angle. The SO state shows a dihedral angle values of around $180^{\circ}$ (table 6). In this electronic state, we have a flat molecule (Cs symmetry). In T1 state, the molecule is non-plane (symmetry C1), the dihedral angle values are around $100^{\circ}$ very different of the planar, $0^{\circ}$ or $180^{\circ}$ (table 6 ).

Bond length: We notice that $\mathbf{C}-\mathbf{H}$, and $\mathbf{O}-\mathbf{H}$ bond lengths are always longer in state $\mathrm{SO}$ than in state $\mathrm{T} 1, \mathbf{C}-\mathbf{O}$ bond length is greater in T1 state than in SO state (table 6 and Figure 5), and for the S0 state and T1 state (graphic7) we have the following order for bond lengths of monohydroxycarbene: The length of $\mathbf{C}-\mathbf{O}$ bond is the highest then come $\mathbf{C}-\mathbf{H}$ and $\mathbf{O}-\mathbf{H}$ distances regardless the method of calculation used.

Bond Angle: Our calculations with different methods (graphic 7) give: the $\square \square$ angle greater than the $\square$ angle in S0 state, while in T1 state, we observe an opposite comportment.

\section{Dihalogenocarbenes}

\section{Bond Length:}

Length C-X: For dihalogenocarbenes, we will focus first on the $\mathbf{C}-\mathbf{X}$ bond length. The results are listed on table 7 and Figure 8 . The interpretation of table 7 and Figure 8 leads us to conclude that for chlorine, the $\mathbf{C}-\mathbf{X}$ bond is faintly longer in S0 state than in $\mathrm{T} 1$ state regardless to the method used.

In contrast to fluorine it is slightly higher at T1 state than at S0 state. Balázs and al. (2000) have achieved the same results than we, because they showed that $\mathrm{C}-\mathrm{X}(\mathrm{X}=\mathrm{Y}=\mathrm{Cl})$ binding of the dihalogenocarbenes was longer in S0 state than in T1 state, and for difluorocarbene, $\mathbf{C}-\mathbf{F}(\mathrm{X}=\mathrm{Y}=\mathrm{F})$ was longer in $\mathrm{T} 1$ 
state than in S0 state (R.W.ALDER et al., 1982). Table 7.

Whatever the methods used, we always found the CCI2 compound had a bond length higher in SO state than in T1 state, but for CF2, we have an opposite behavior.

Bond Angle: For these types of carbènes, table 8 and Figure 9, allow us to say that bond angles are larger at the $\mathrm{T} 1$ state than at S0 state regardless to the method used. In T1 state, they are smaller than methylene with the values of fluorine lower than $120^{\circ}$. In S0 state, these angles are larger than that of methylene, fluorine having its angle lower than the other's. Our results are conform to those of Balázs and al. (2000), Karl and al. (1992) who found, that $Y$ $\mathrm{C}-\mathrm{X}(\mathrm{X}=\mathrm{Y}=\mathrm{F}, \mathrm{Cl})$ bond angles are very larger in triplet state than in singlet state.

The bond angle increases also with the atomic number of the element. The results of the literature (Jacox and Milligan, 1970) Dixon and Simon, 1970; (Shultz and al., 1979, 1982) Mathews, 1966, 1967; Powell and Lide, 1966; Kirchhoff and al., 1973; Bondybey, 1976, Ishiguro and al. 1981; Maltsev and al... 1971; Hastie and al. 1969; Milligan and Jacox, 1967; Vaida, 1976; UY and al. (1969) are also in agreement with our calculations.

Dihydroxycarbene: For dihydroxycarbene, we have three possible conformations: (dihedral angle $\mathrm{H} 3, \mathrm{O} 2$, $\mathrm{C} 1, \mathrm{O} 4, \mathrm{H} 5=180^{\circ}$ : conformer $\mathrm{Z} ;=0^{\circ}$ : conformer $Z^{\prime}$ and $\neq 0^{\circ}$ and $180^{\circ}$ conformer E) (Figure 6)

Concerning the $\mathrm{S} 0$ state, $\mathrm{Z}$ and $\mathrm{E}$ conformations are flat. $E$ has $C$ s symmetry and $Z$ has $C 2 v$ symmetry. About the $\mathrm{T} 1$ state, $\mathrm{Z}$ and $\mathrm{E}$ are $\mathrm{C}_{2}$ symmetry, both $\mathrm{OH}$ are then a dihedral angle around $154^{\circ}$. Con $\mathrm{Z}$ conformation, dihedral angle measures $0^{\circ}$. The geometrical parameters of these different conformers are shown on figure 7 and grouped in tables 9, 10 and 11.

Geometrical parameters of different conformers are grouped in tables 9,10 and 11 . We found that $a=02$ -
$\mathrm{C} 1$ and $\mathrm{b}=\mathrm{C} 1$ - $\mathrm{O} 4$ bond lengths, are always smaller in S0 state than in T1 state for conformations Z, and $E$ in all levels of theory, except for the G3 level of theory with $E$ conformation where bond length $b$ is smaller in the $\mathrm{T} 1$ state than in S0 state. $(\mathrm{C}=\mathrm{O} 1$ $\mathrm{H} 5$ ) bond length is smaller in the SO state than in state $\mathrm{T} 1$ for $\mathrm{Z}$ conformation and for $\mathrm{E}$ conformation with the Composed and B3LYP methods, but for Z' conformation we observe the opposite behavior whatever the levels of theories used.

$\mathrm{d}=\mathrm{O} 2-\mathrm{H} 3$ bond length is smaller in the S0 state and $\mathrm{T} 1$ state for $\mathrm{Z}$ conformation in all the levels of theories and for the $E$ conformation with $\mathrm{HF}$ and B3LYP methods. For conformation ' $Z^{\prime}$ in all methods and $E$ conformation with the composed methods, we observe a contrary development:

$\alpha, \beta$, and $\varphi$ bond angles are generally higher in T1 state than in the $S 0$ state for $Z$ and $E$ conformations.

In the composed and HF methods, bond angle $\beta$ is higher in the S0 state than in the T1 state for conformation E. In Z' conformation, the bond $\alpha$ angle is higher in the T1 than in the S0 state while $\beta$ and $\varphi$ bond angles observed the opposite behavior.

The atoms $\mathrm{O}, \mathrm{C}$, and $\mathrm{O}$ common member of the three conformations, have $\mathrm{C}_{2} \mathrm{~V}$ symmetry regardless the electronic state ( $\mathrm{S} 0$ or $\mathrm{T} 1$ ). In T1 state, we note that geometric parameters of $Z$ are identical to those of $E$ (tables 9 and 10). In this state, there is therefore only one electron state that corresponds to the conformation $\mathrm{E}$ or $\mathrm{Z}$. In the SO state, the dihydroxycarbene has a dihedral angle $(\mu 3)$ value $180^{\circ}$ for $E$ and, $\approx 0^{\circ}$ for $Z$ and $Z$ ' conformations. These values show that the dihydroxycarbene is Planar in state S0. In the T1 state the molecule is non-planar because the dihedral angle $\mu 3$ is less than $180^{\circ}$. We note also that in the $Z$ and ' ' conformations, we have bond lengths $a=b$ and $c=$ $\mathrm{d}, \beta \sqcap$ and $\varphi$ bond angles and dihedral angles $\mu 1$ and $\mu 2$ are also equal pairwise whatever the state considered. In the general case, geometrical parameters vary very little with the methods used.

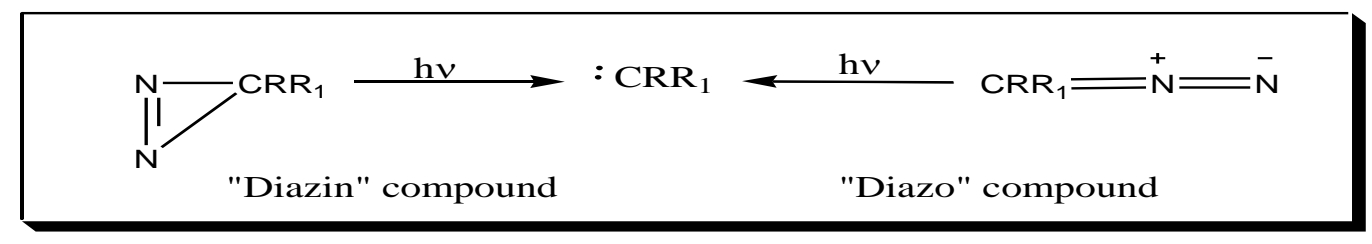

Fig.1: Photolysis of "diazo" or "DIAZIRIN." 


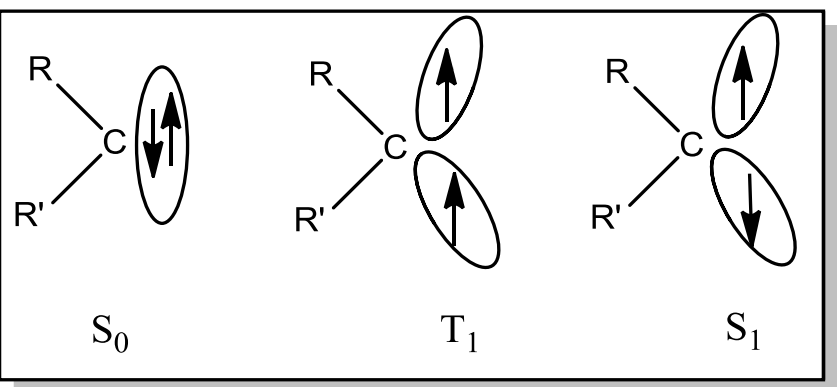

Fig.2: electronic states of carbenes (State S0, state S1 and state T1)

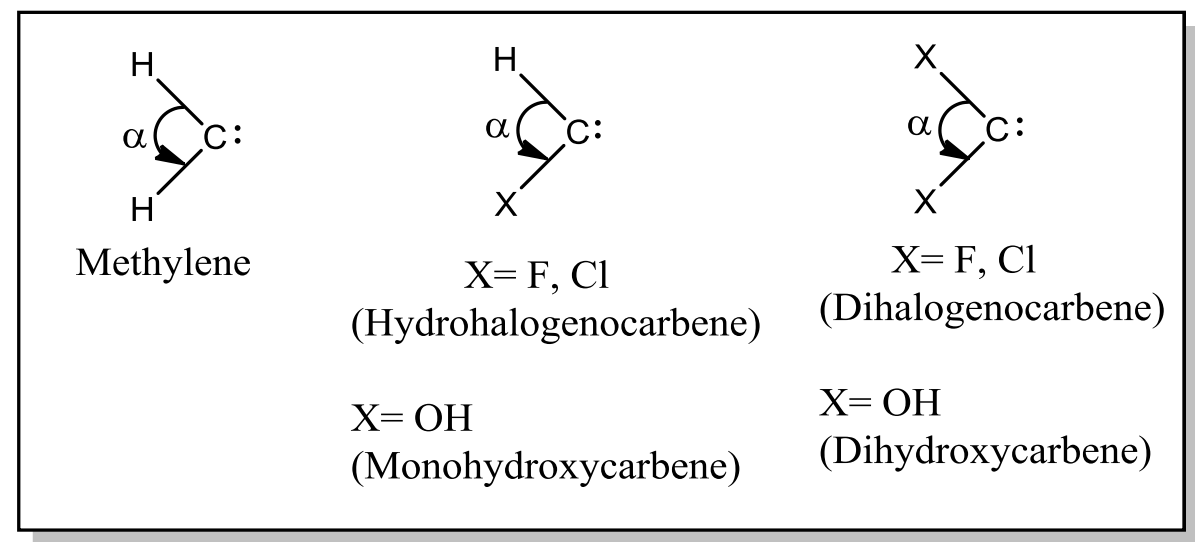

Fig.3: Studied Carbenes

Table. 1: Length of C - H bond in ( $\AA$ ) methylene based methods with the core cc-pVTZ

\begin{tabular}{|l|l|l|l|l|l|l|}
\hline & $\mathrm{HF}^{\mathrm{a}}$ & $\mathrm{MP2}^{\mathrm{a}}$ & DFT $\left.^{\left(B 3 \mathrm{LYP}^{\mathrm{a}}\right.}\right)$ & G3 $^{\mathrm{b}}$ & CBS-Q $^{b}$ & CBS-APNO $^{b}$ \\
\hline & $\mathrm{C}-\mathrm{H}$ & $\mathrm{C}-\mathrm{H}$ & $\mathrm{C}-\mathrm{H}$ & $\mathrm{C}-\mathrm{H}$ & $\mathrm{C}-\mathrm{H}$ & $\mathrm{C}-\mathrm{H}$ \\
\hline $\mathrm{CH}_{2} \mathrm{~S} 0(\mathrm{LS} 0)$ & 1,096 & 1,104 & 1,110 & 1,109 & 1,114 & 1,116 \\
\hline $\mathrm{CH}_{2} \mathrm{~T}_{1}(\mathrm{LT} 1)$ & 1,070 & 1,074 & 1,078 & 1,077 & 1,081 & 1,082 \\
\hline LS0 - LT1 & 0,026 & 0,031 & 0,033 & 0,032 & 0,032 & 0,034 \\
\hline
\end{tabular}

Bond length in $\AA$, a $=$ cc-pVTZ, b geometries obtained albeit at a lower level 


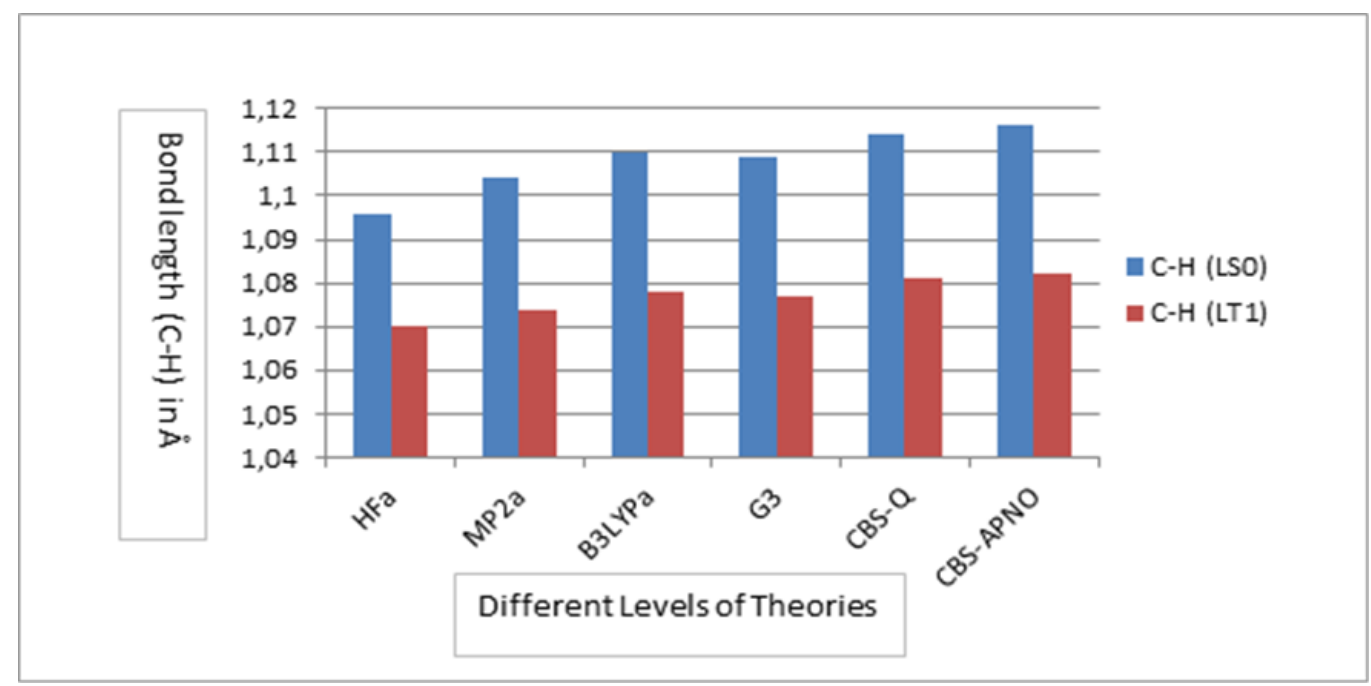

Graphic.1: Variation of H-C-H bond length of methylene by different methods.

$$
\left\{\begin{array}{c}
\alpha_{s p}>\alpha_{s p 2}>\alpha_{s p 3} \\
\alpha_{T_{1}} \text { is beetween } \alpha_{s p} \text { and } \alpha_{s p 2} \leftrightarrow \alpha_{\mathrm{T}_{1}}>\alpha_{\mathrm{S}_{0}} \\
\alpha_{\mathrm{S}_{0}}=\alpha_{s p 3}
\end{array}\right.
$$

Fig.4: Evolution of bonding angle in states $\mathrm{T} 1$ and $\mathrm{S} 0$ states in comparison with that of hybridizations

Table 2: Bond Angle $\mathrm{H}-\mathrm{C}-\mathrm{H}$ in degrees $\left(^{\circ}\right)$ of the various structures of methylene obtained with different levels theory with the cc-pVTZ basis set.

\begin{tabular}{|l|l|l|l|l|l|l|}
\hline & $\mathrm{HF}^{\mathrm{a}}$ & $\mathrm{MP2}^{\mathrm{a}}$ & $\mathrm{DFT}\left(\mathrm{B} 3 \mathrm{LYP}^{\mathrm{a}}\right)$ & $\mathrm{G} 3$ & $\mathrm{CBS}-\mathrm{Q}$ & CBS-APNO \\
\hline & $\mathrm{HCH}$ & $\mathrm{HCH}$ & $\mathrm{HCH}$ & $\mathrm{HCH}$ & $\mathrm{HCH}$ & $\mathrm{HCH}$ \\
\hline $\mathrm{CH}_{2} \mathrm{SO}(\alpha \mathrm{S} 0)$ & 103,6 & 101,8 & 101,6 & 102,6 & 101,3 & 101,0 \\
\hline $\mathrm{CH}_{2} \mathrm{~T}_{1}\left(\alpha \mathrm{T}_{1}\right)$ & 131,8 & 132,8 & 134,9 & 131,6 & 131,7 & 132,6 \\
\hline$\alpha \mathrm{T}_{1}-\alpha \mathrm{SO} 0$ & 28,2 & 30,9 & 33,3 & 29,0 & 30,4 & 31,6 \\
\hline
\end{tabular}


Am. J. Sci. Ind. Res., 2012, 3(3): 128-145

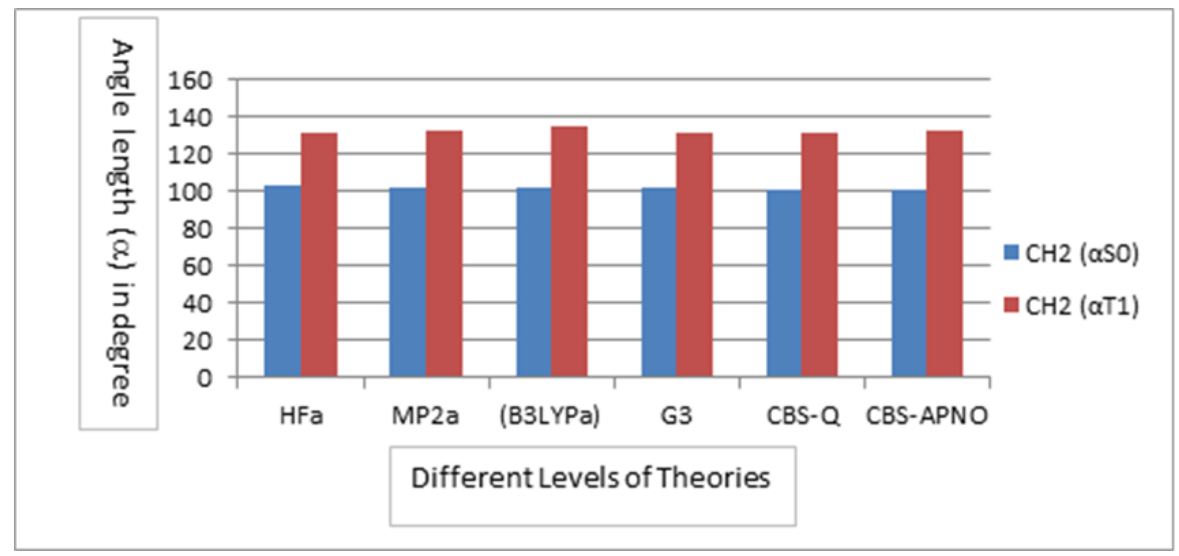

Graphic 1bis: Variation of the angle of $\mathrm{H}-\mathrm{C}-\mathrm{H}$ bond of methylene by different quantum methods calculations.

Table. 3: CX bond length of different states of the Hydrohalogenocarbenes with the five theoretical levels, the authors and the experience data.

\begin{tabular}{|l|l|l|l|l|l|l|l|}
\hline & HF $^{\mathrm{a}}$ & MP2 & G3 & CBS-Q & B3LYP & $\begin{array}{l}\text { Result of Balázs } \\
\text { and al }\end{array}$ & Experience \\
\hline Y---X Etat & C-X & C-X & C-X & C-X & C-X & C-X & C-X \\
\hline H--F S0 & 1,285 & 1,305 & 1,319 & 1,310 & 1,310 & 1,317 & $1,314^{\mathrm{c}}$ \\
\hline H--Cl S0 & 1,699 & 1,687 & 1,695 & 1,699 & 1,707 & 1,707 & $1,689-1,696^{\mathrm{d}}$ \\
\hline H--F T & 1,300 & 1,313 & 1,328 & 1,320 & 1,313 & 1,321 & $1,321^{e^{e}}$ \\
\hline H--Cl T & 1,681 & 1,602 & 1,671 & 1,675 & 1,665 & 1,678 & $1,735^{\dagger}$ \\
\hline
\end{tabular}

Angstrom, bond length $a=c c-p V T Z, b=$ (Balázs and Coll., 2000), $c=$ (Herzberg, 1972; Merer and Travis, 1966; Jacox and Milligan, 1969; Samsonov and Petrov, 1981), $d=$ (Merer and Travis, 1966; Jacox and Milligan, 1967, 1970; Kakimoto et al. , 1981, 1983, 1990), e= (Goldfield and Simon, 1961; Dixon and Simon, 1970), f= (Dixon and Simon, 1970).

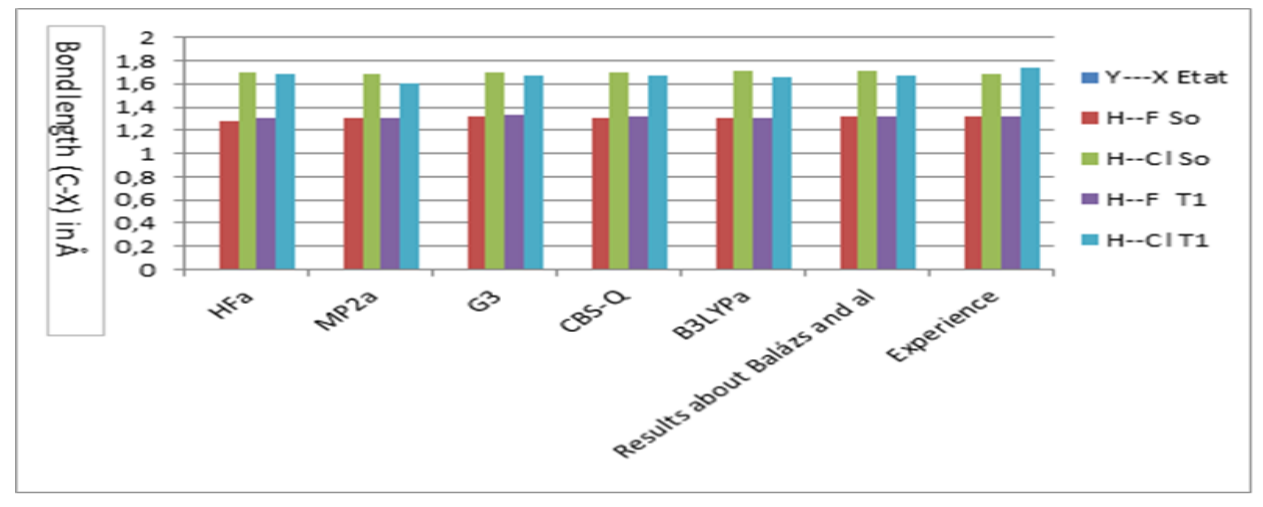

Graphic 2: Variation of CX bond length of different states of the Hydrohalogenocarbenes with the five theoretical levels, the authors and the experience data. 
Am. J. Sci. Ind. Res., 2012, 3(3): 128-145

Table 4: $\mathrm{C}-\mathrm{H}$ bond length of different states of the Hydrohalogenocarbenes with the five theoretical levels, the authors and the experience data.

\begin{tabular}{|c|c|c|c|c|c|c|c|}
\hline & $\mathrm{HF}^{\mathrm{a}}$ & $\mathrm{MP2}^{\mathrm{a}}$ & G3 & CBS-Q & B3LYPa & Results about Balázs and al $\left.\right|^{b}$ & Experience \\
\hline$\overline{Y---X}$ & $\mathrm{C}-\mathrm{H}$ & $\mathrm{C}-\mathrm{H}$ & $\mathrm{C}-\mathrm{H}$ & $\mathrm{C}-\mathrm{H}$ & $\mathrm{C}-\mathrm{H}$ & $\mathrm{C}-\mathrm{H}$ & $\mathrm{C}-\mathrm{H}$ \\
\hline $\mathrm{H}-\mathrm{F} \mathrm{SO}$ & 1,104 & 1,116 & 1,121 & 1,126 & 1,124 & 1,127 & $1,12^{\mathrm{C}}$ \\
\hline $\mathrm{H}-\mathrm{Cl} \mathrm{SO}$ & 1,092 & 1,105 & 1,109 & 1,114 & 1,109 & 1,116 & $1,119-1,120^{d}$ \\
\hline $\mathrm{H}-\mathrm{F} \mathrm{T}_{1}$ & 1,074 & 1,082 & 1,085 & 1,090 & 1,089 & 1,091 & $1,077^{\mathrm{e}}$ \\
\hline $\mathrm{H}-\mathrm{Cl} \mathrm{T}_{1}$ & 1,071 & 1,079 & 1,082 & 1,086 & 1,083 & 1,087 & $1,075^{\dagger}$ \\
\hline
\end{tabular}

Bonds length in Angstrom, a=cc-pVTZ, b= (Balázs et Coll. ,2000), c= (Herzberg, 1972 ; Merer and Travis, 1966 ; Jacox and Milligan, 1969 ; Samsonov and Petrov, 1981), d= (Merer et Travis, 1966 ; Jacox and Milligan, 1967, 1970 ; Kakimoto et al., 1981 ,1983 ,1990), e= (Goldfield and Simon, 1961 ; Dixon and Simon, 1970) , f=(Dixon and Simon, 1970).

Angstrom, bond length $a=c c-p V T Z, b=$ (Balázs et Coll., 2000), $c=$ (Herzberg, 1972; Merer and Travis, 1966; Jacox and Milligan, 1969; Samsonov and Petrov, 1981), d= (Merer et Travis, 1966; Jacox and Milligan, 1967, 1970; Kakimoto et al. , 1981, 1983, 1990), e= (Goldfield and Simon, 1961; Dixon and Simon, 1970), f= (Dixon and Simon, 1970).

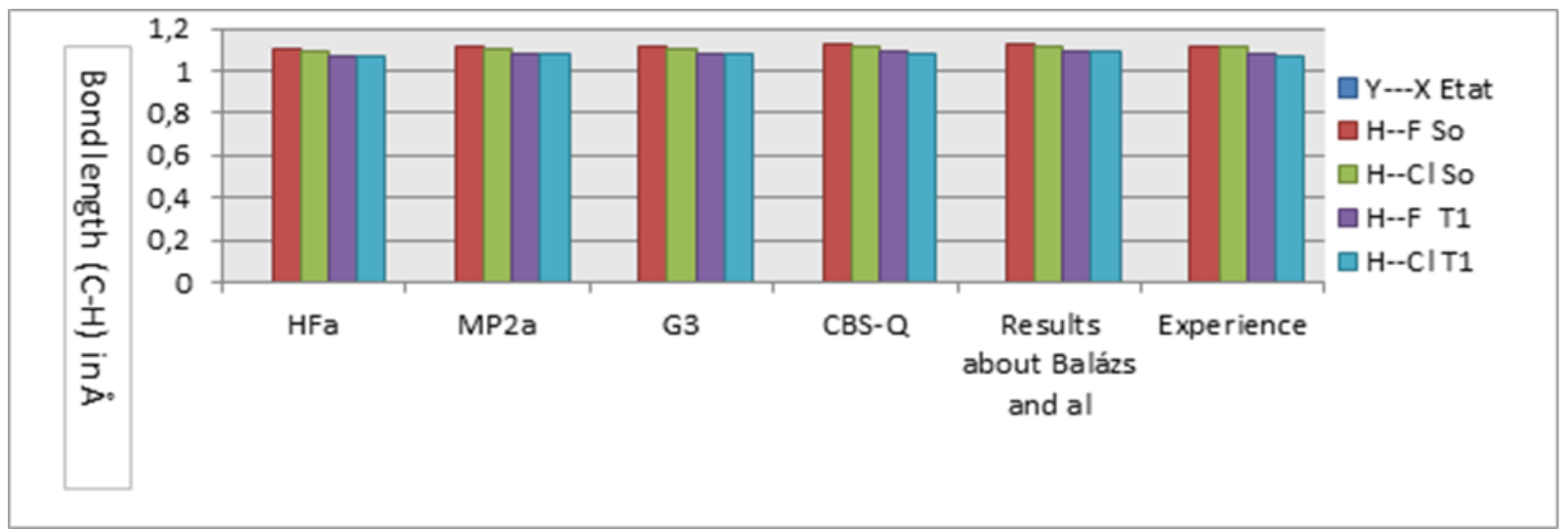

Graphic 3: Variation of $\mathrm{C}-\mathrm{H}$ bond length of different states of the Hydrohalogenocarbenes with the five theoretical levels, the authors and the experience data. 
Am. J. Sci. Ind. Res., 2012, 3(3): 128-145

Table. 5: Bond angle $\mathrm{H}-\mathrm{C}-\mathrm{X}$ in degree $\left({ }^{\circ}\right)$ of different states of the Hydrohalogenocarbenes with the five theoretical levels, the authors and the experience data.

\begin{tabular}{|c|c|c|c|c|c|c|c|c|}
\hline & $\mathrm{HF}^{\mathrm{a}}$ & $\mathrm{MP}^{\mathrm{a}}$ & G3 & $\begin{array}{l}\text { CBS- } \\
Q\end{array}$ & B3LYP ${ }^{a}$ & $\begin{array}{l}\text { Results } \\
\text { about Karl k }\end{array}$ & $\begin{array}{l}\text { Results about } \\
\text { Balázs and } \mathrm{al}^{\circ}\end{array}$ & litterature \\
\hline $\begin{array}{l}\text { Y---X } \\
\text { Etat }\end{array}$ & $\mathrm{H}-\mathrm{C}-\mathrm{X}$ & $\begin{array}{l}\mathrm{H}-\mathrm{C}- \\
\mathrm{X}\end{array}$ & $\begin{array}{l}\mathrm{H}-\mathrm{C}- \\
X\end{array}$ & $\begin{array}{l}\mathrm{H}-\mathrm{C}- \\
X\end{array}$ & $\mathrm{H}-\mathrm{C}-\mathrm{X}$ & $\mathrm{H}-\mathrm{C}-\mathrm{X}$ & $\mathrm{H}-\mathrm{C}-\mathrm{X}$ & $\mathrm{H}-\mathrm{C}-\mathrm{X}$ \\
\hline H--F S0 & 103,4 & 102,3 & 102,0 & 102,1 & 102,2 & 102,2 & 102,0 & $101,8^{\mathrm{C}}$ \\
\hline $\mathrm{H}-\mathrm{Cl}$ SO & 103,5 & 102,2 & 103,0 & 102,4 & 102,0 & 101,4 & 102,3 & $101-103^{d}$ \\
\hline $\mathrm{H}--\mathrm{F} \mathrm{T}_{1}$ & 121,6 & 121,5 & 121,2 & 121,2 & 121,2 & 120,6 & 121,3 & $120,4^{\mathrm{e}}$ \\
\hline $\mathrm{H}--\mathrm{Cl} \mathrm{T}_{1}$ & 125,8 & 126,3 & 125,8 & 129,6 & 126,7 & 123,7 & 125,8 & $123,3^{\dagger}$ \\
\hline
\end{tabular}

Bond angle in degree, $a=c c-p V T Z, k=($ Karl et Coll ,1992), $b=$ (Balázs et Coll. ,2000), $c=$ (Herzberg, 1972 ; Merer and Travis, 1966 ; Jacox and Milligan, 1969 ; Samsonov and Petrov, 1981), $d=$ (Merer et Travis, 1966 ; Jacox and Milligan, 1967, 1970 ; Kakimoto et al., 1981, 1983 ,1990), e= (Goldfield and Simon, 1961; Dixon and Simon, 1970), $f=$ (Dixon and Simon, 1970).

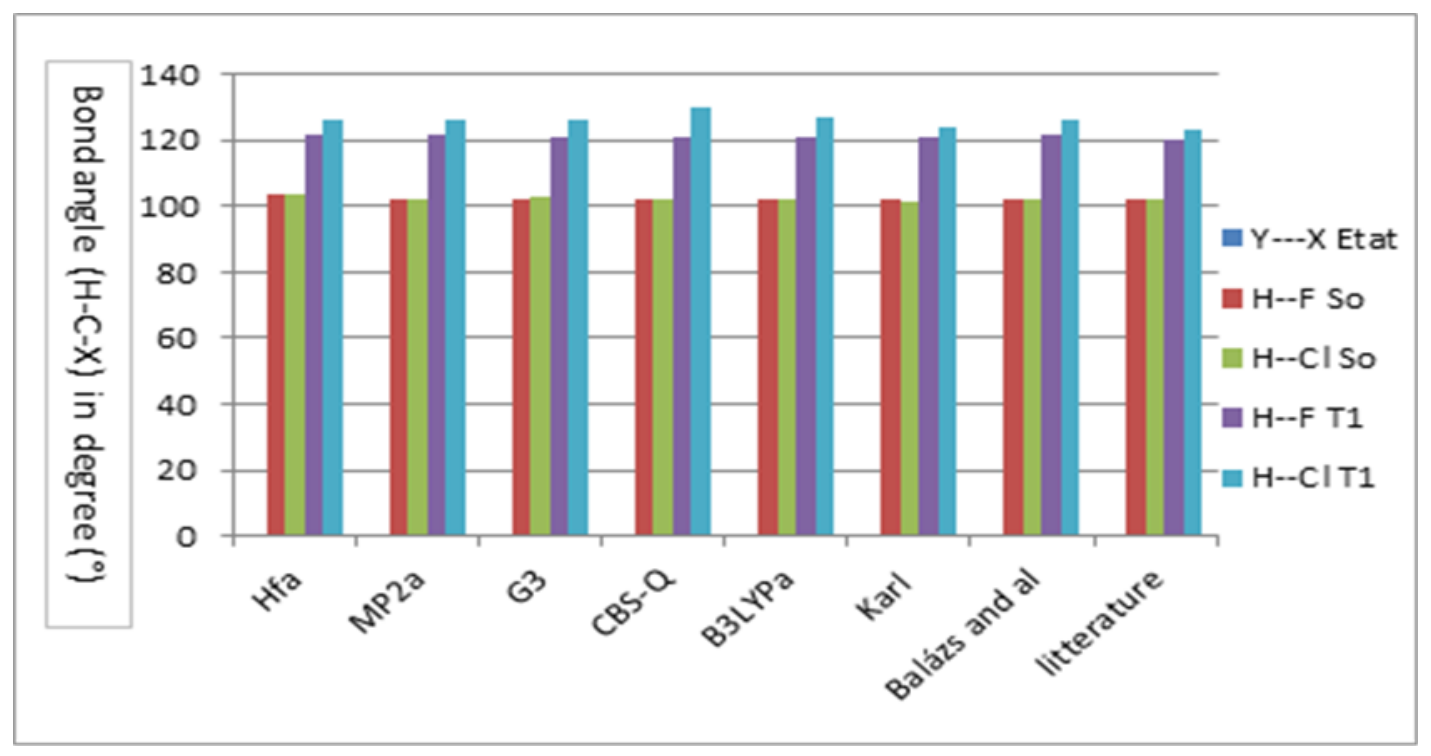

Graphic. 4: Variation of the bond angle H-C-X of different states of the Hydrohalogenocarbenes with the five theoretical levels, the authors and the experience data. 
Table 6: Geometry of the monohydroxycarbene in (HF, MP2, B3LYP, G3, CBS - Q, CBS-APNO) levels of theory

\begin{tabular}{|c|c|c|c|c|c|c|c|}
\hline & & length $\mathrm{E}$ & $\mathrm{C}-\mathrm{H}$ & & length $A$ & & $\begin{array}{l}\text { diehedral } \\
\text { Angle }\end{array}$ \\
\hline & Methode & $a=C-H$ & $b=C-O$ & $\mathrm{c}=\mathrm{O}-\mathrm{H}$ & $\alpha=\mathrm{HCO}$ & $\beta=\mathrm{COH}$ & $\delta=\mathrm{HCOH}$ \\
\hline S0 state & $\mathrm{HF}^{\mathrm{a}} \mathrm{SO}$ & 1,099 & 1,292 & 0,944 & 103,8 & 109,9 & $-180,0$ \\
\hline & $\mathrm{MP2}^{\mathrm{a}} \mathrm{S} 0$ & 1,108 & 1,313 & 0,967 & 102,1 & 107,0 & 180,1 \\
\hline & G3 S0 & 1,113 & 1,322 & 0,977 & 101,5 & 107,3 & 180,0 \\
\hline & CBS-Q S0 & 1,118 & 1,317 & 0,970 & 101,5 & \begin{tabular}{|l|}
107,7 \\
\end{tabular} & 180,0 \\
\hline & $\begin{array}{l}\text { CBS-APNO } \\
\text { s0 }\end{array}$ & 1,118 & 1,318 & 0,964 & 101,8 & 107,0 & 180,0 \\
\hline & B3LYP ${ }^{a}$ S0 & 1,114 & 1,311 & 0,969 & 102,3 & 108,6 & $-180,0$ \\
\hline $\mathrm{T}_{1}$ state & $\mathrm{HF}^{\mathrm{a}} \mathrm{T}_{1}$ & 1,077 & 1,332 & 0,943 & 124,3 & 111,5 & 99,5 \\
\hline & $\mathrm{MP}^{\mathrm{a}} \mathrm{T}_{1}$ & 1,085 & 1,339 & 0,965 & 124,0 & 109,8 & 102,1 \\
\hline & G3 $T_{1}$ & 1,089 & 1,347 & 0,975 & 123,5 & 110,1 & 101,8 \\
\hline & CBS-Q T & 1,094 & 1,343 & 0,969 & 123,5 & 110,6 & 101,4 \\
\hline & $\begin{array}{l}\text { CBS-APNO } \\
\mathrm{T}_{1}\end{array}$ & 1,080 & 1,345 & 0,962 & 123,6 & 108,9 & 101,7 \\
\hline & $\mathrm{B}^{2} \mathrm{LYP}^{\mathrm{a}} \mathrm{T}_{1}$ & 1,091 & 1,332 & 0,969 & 123,9 & 112,0 & 102,1 \\
\hline
\end{tabular}

Bond lengths in Angstrom, degree, bond angle $\mathrm{a}=\mathrm{cc}-\mathrm{pvtz}$ 
Am. J. Sci. Ind. Res., 2012, 3(3): 128-145
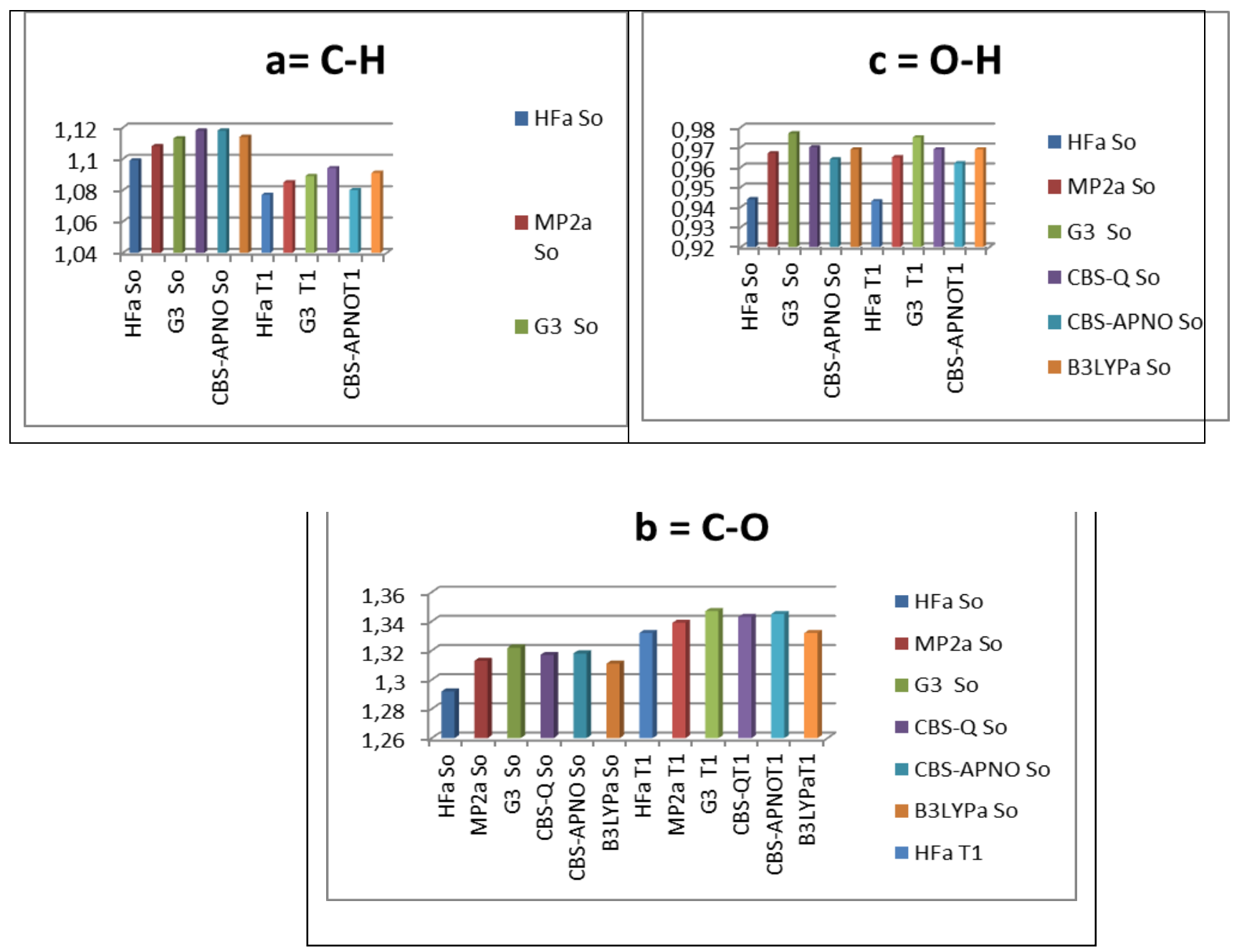

Graphic 5: Variation of bond lengths $(\mathrm{a}=\mathrm{C}-\mathrm{H}, \mathrm{b}=\mathrm{C}=\mathrm{O}-\mathrm{H} \mathrm{C}-\mathrm{O})$ of the monohydroxycarbene with the different levels of theory.

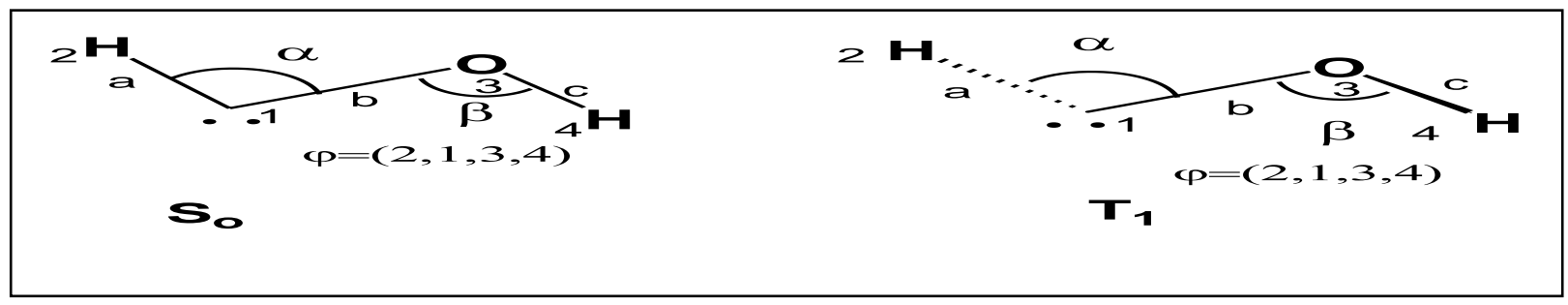

Fig.5 Schematic representation of optimized geometries of state S0 and state $\mathrm{T} 1$ of monohydroxycarbene 
Table 6: Geometry of the monohydroxycarbene in (HF, MP2, B3LYP, G3, CBS - Q, CBS-APNO) levels of theory

\begin{tabular}{|c|c|c|c|c|c|c|c|}
\hline & & length $\mathrm{E}$ & $\mathrm{C}-\mathrm{H}$ & & length $A$ & & $\begin{array}{l}\text { dihedral } \\
\text { Angle }\end{array}$ \\
\hline & Method & $\mathrm{a}=\mathrm{C}-\mathrm{H}$ & $\mathrm{b}=\mathrm{C}-\mathrm{O}$ & $\mathrm{c}=\mathrm{O}-\mathrm{H}$ & $\alpha=\mathrm{HCO}$ & $\beta=\mathrm{COH}$ & $\delta=\mathrm{HCOH}$ \\
\hline So state & $\mathrm{HF}^{\mathrm{a}} \mathrm{SO}$ & 1,099 & 1,292 & 0,944 & 103,8 & 109,9 & $-180,0$ \\
\hline & $\mathrm{MP2}^{\mathrm{a}} \mathrm{SO}$ & 1,108 & 1,313 & 0,967 & 102,1 & 107,0 & 180,1 \\
\hline & G3 S0 & 1,113 & 1,322 & 0,977 & 101,5 & 107,3 & 180,0 \\
\hline & CBS-Q S0 & 1,118 & 1,317 & 0,970 & 101,5 & \begin{tabular}{|l|}
107,7 \\
\end{tabular} & 180,0 \\
\hline & $\begin{array}{l}\text { CBS-APNO } \\
\text { S0 }\end{array}$ & 1,118 & 1,318 & 0,964 & 101,8 & 107,0 & 180,0 \\
\hline & $\mathrm{B}^{2} \mathrm{LYP}^{\mathrm{a}} \mathrm{S} 0$ & 1,114 & 1,311 & 0,969 & 102,3 & 108,6 & $-180,0$ \\
\hline $\mathrm{T}_{1}$ state & $\mathrm{HF}^{\mathrm{a}} \mathrm{T}_{1}$ & 1,077 & 1,332 & 0,943 & 124,3 & 111,5 & 99,5 \\
\hline & $\mathrm{MP}^{\mathrm{a}} \mathrm{T}_{1}$ & 1,085 & 1,339 & 0,965 & 124,0 & 109,8 & 102,1 \\
\hline & G3 $T_{1}$ & 1,089 & 1,347 & 0,975 & 123,5 & 110,1 & 101,8 \\
\hline & CBS-Q $T_{1}$ & 1,094 & 1,343 & 0,969 & 123,5 & 110,6 & 101,4 \\
\hline & $\begin{array}{l}\text { CBS-APNO } \\
T_{1}\end{array}$ & 1,080 & 1,345 & 0,962 & 123,6 & 108,9 & 101,7 \\
\hline & $\mathrm{B} \mathrm{LYY} \mathrm{P}^{\mathrm{a}} \mathrm{T}_{1}$ & 1,091 & 1,332 & 0,969 & 123,9 & 112,0 & 102,1 \\
\hline
\end{tabular}

Bond lengths in Angstrom, degree, bond angle $\mathrm{a}=\mathrm{cc}-\mathrm{pvtz}$

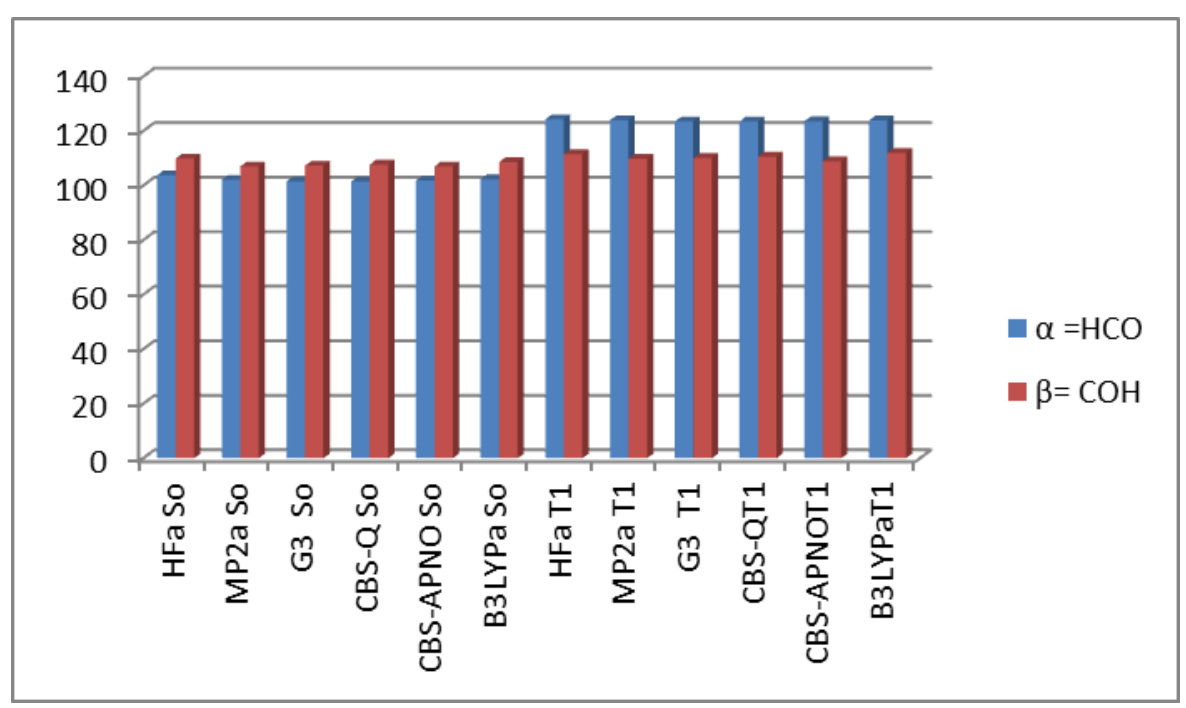

Graphic 7: Variation of angles $\alpha$ and $\beta$ in SO and T1 states of monohydroxycarbenes with the five theoretical levels 
Am. J. Sci. Ind. Res., 2012, 3(3): 128-145

Table.7: C - X Bond length of the different states of the dihalogenocarbene with five theoretical levels, the authors and the experience data.

\begin{tabular}{|c|c|c|c|c|c|c|c|}
\hline & $\mathrm{HF}^{\mathrm{a}}$ & $\mathrm{MP}^{\mathrm{a}}$ & G3 & CBS-Q & $B 3 L Y P^{a}$ & $\begin{array}{c}\text { Balázs and } \\
\mathrm{al}^{\mathrm{b}}\end{array}$ & Litterature \\
\hline Y---X Etat & $C-X=C-Y$ & $C-X=C-Y$ & $C-X=C-Y$ & $C-X=C-Y$ & $\mathrm{C}-\mathrm{X}=\mathrm{C}-\mathrm{Y}$ & $\mathrm{C}-\mathrm{X}=\mathrm{C}-\mathrm{Y}$ & $C-X=C-Y$ \\
\hline F--F S & 1,273 & 1,299 & 1,313 & 1,305 & 1,304 & 1,307 & $1,3^{9}$ \\
\hline $\mathrm{Cl}--\mathrm{Cl} \mathrm{S}$ o & 1,706 & 1,712 & 1,716 & 1,720 & 1,734 & 1,73 & $1,70-1,758^{n}$ \\
\hline $\mathrm{F}-\mathrm{F} \quad \mathrm{T}_{1}$ & 1,295 & 1,315 & 1,327 & 1,320 & 1,318 & 1,321 & $1,305^{j}$ \\
\hline $\mathrm{Cl}-\mathrm{Cl} \mathrm{T}$ & 1,684 & 1,675 & 1,679 & 1,684 & 1,683 & 1,690 & $1,73^{\dagger}$ \\
\hline
\end{tabular}

Length bond in Angstrom, a= cc-pVTZ, $b=$ (Balázs et Coll., 2000), $\mathrm{g}=($ Shultz and al ., 1979, 1982 ;Mathews ,1966 1967 ; Powell and Lide,1966 ; Kirchhoff and al., 1973 ;Bondybey, 1976 ;Ishiguro and al. , 1981 ) ,h=(Jacox and Milligan, 1970 ; Shultz and al., 1979, 1982 ;Maltsev and al.. ,1971 ; Hastie and al. ,1969 ; Milligan and Jacox, 1967 ) , j=(Vaida, 1976 ;Uy and al. , 1969 ) , f=(Dixon and Simon, 1970

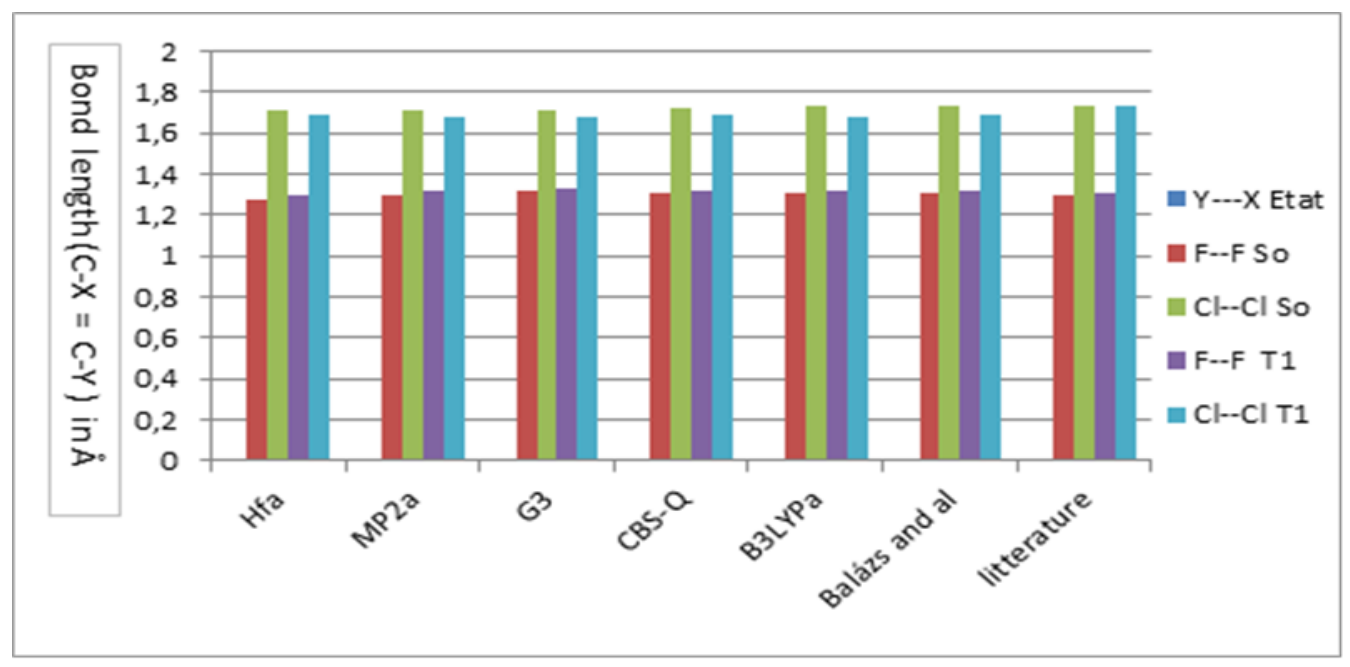

Graphic. 8: Variation of bond lengths of dihalogenocarbene with the five theoretical levels, the authors and the experience data.

Table. 8: Y-C-X bond angle of S0 and T1 states of the dihalogenocarbenes with the five theoretical levels, the authors and the experience data.

\begin{tabular}{|c|c|c|c|c|c|c|c|c|}
\hline & $\mathrm{HF}^{\mathrm{a}}$ & $\mathrm{MP}^{\mathrm{a}}$ & G3 & CBS-Q & $B 3 L Y P^{a}$ & Karl and al. & $\begin{array}{l}\text { Balázs } \\
\text { and al. b }\end{array}$ & litterature \\
\hline Y---X Etat & $\mathrm{Y}-\mathrm{C}-\mathrm{X}$ & $\mathrm{Y}-\mathrm{C}-\mathrm{X}$ & $\mathrm{Y}-\mathrm{C}-\mathrm{X}$ & $\mathrm{Y}-\mathrm{C}-\mathrm{X}$ & $\mathrm{Y}-\mathrm{C}-\mathrm{X}$ & $\mathrm{Y}-\mathrm{C}-\mathrm{X}$ & $\mathrm{Y}-\mathrm{C}-\mathrm{X}$ & $\mathrm{Y}-\mathrm{C}-\mathrm{X}$ \\
\hline F-F So & 105,1 & 105,0 & 104,2 & 104,7 & 104,7 & 104,0 & 104,7 & $104,34-104,78^{9}$ \\
\hline $\mathrm{Cl}-\mathrm{Cl} \mathrm{S}_{\mathrm{o}}$ & 110,1 & 109,3 & 110,0 & 109,6 & 109,3 & 109,0 & 110 & $108^{n}$ \\
\hline $\mathrm{F}-\mathrm{F} \mathrm{T}_{1}$ & 118,3 & 119,4 & 119,8 & 119,8 & 119,7 & 118,0 & 119,1 & $134,5^{\prime}$ \\
\hline $\mathrm{Cl}-\mathrm{Cl} \mathrm{T}$ & 127,0 & 127,5 & 127,6 & 127,3 & 128,4 & 126,1 & 127,5 & $125,5^{\dagger}$ \\
\hline
\end{tabular}


Bond angle in degree, $\mathrm{a}=\mathrm{cc}-\mathrm{pVTZ}, \mathrm{k}=$ (Karl et Coll ' 1992), $\mathrm{b}=$ (Balázs et Coll., 2000), $\mathrm{g}=$ (Shultz and al ., 1979, 1982 ;Mathews ,1966,1967 ; Powell and Lide,1966 ; Kirchhoff and al., 1973 ;Bondybey, 1976 ;Ishiguro and al. , 1981 ) ,h=(Jacox and Milligan, 1970 ; Shultz and al., 1979, 1982 ; Maltsev and al.. ,1971 ; Hastie and al. ,1969 ; Milligan and Jacox, 1967 ) , j=(Vaida, 1976 ;Uy and al. , 1969 ) , f=(Dixon and Simon, 1970).

Bond angle is in degrees, $a=c c-p V T Z, k=$ (Karl et Coll ,1992), $b=$ (Balázs et Coll., 2000), $g=$ (Shultz and al . ,1979, 1982 ;Mathews ,1966,1967 ; Powell and Lide,1966 ; Kirchhoff and al., 1973 ;Bondybey, 1976 ;Ishiguro and al. , 1981 ) ,h=(Jacox and Milligan, 1970 ; Shultz and al., 1979, 1982 ; Maltsev and al.. ,1971 ; Hastie and al. ,1969 ; Milligan and Jacox, 1967 ) , j=(Vaida, 1976 ;Uy and al. , 1969 ) , f=(Dixon and Simon, 1970).

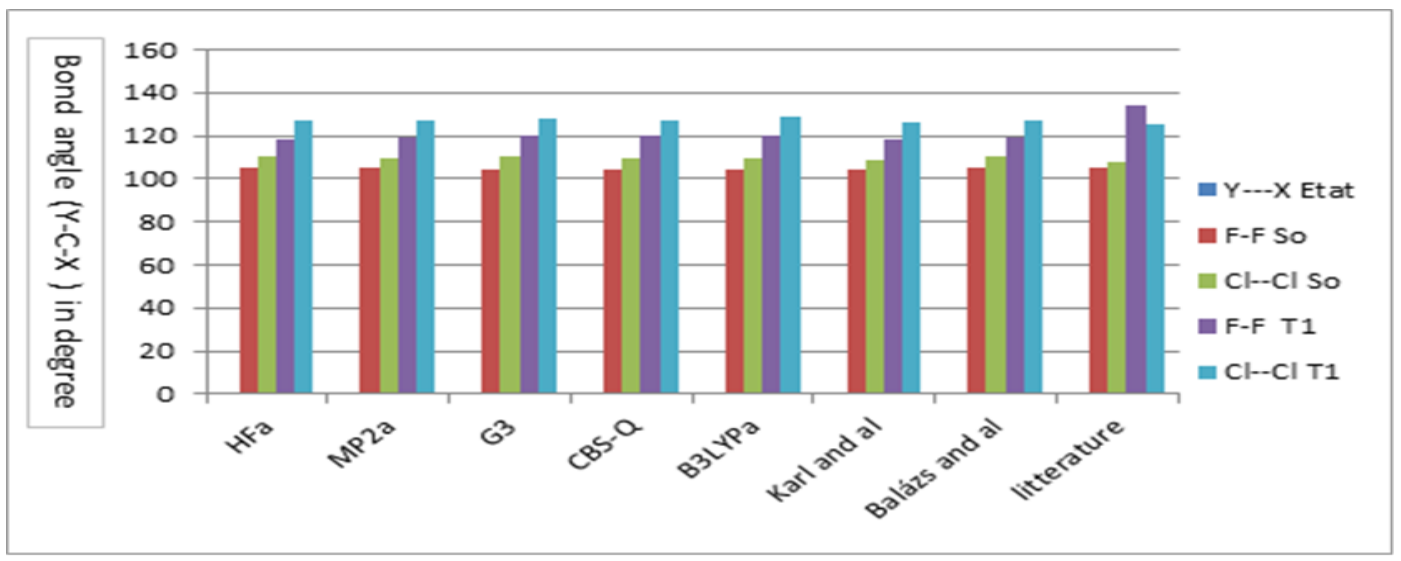

Graphic. 9: Bond angles of dihalogenocarbenes with the five theoretical levels, the literature and the experience data.

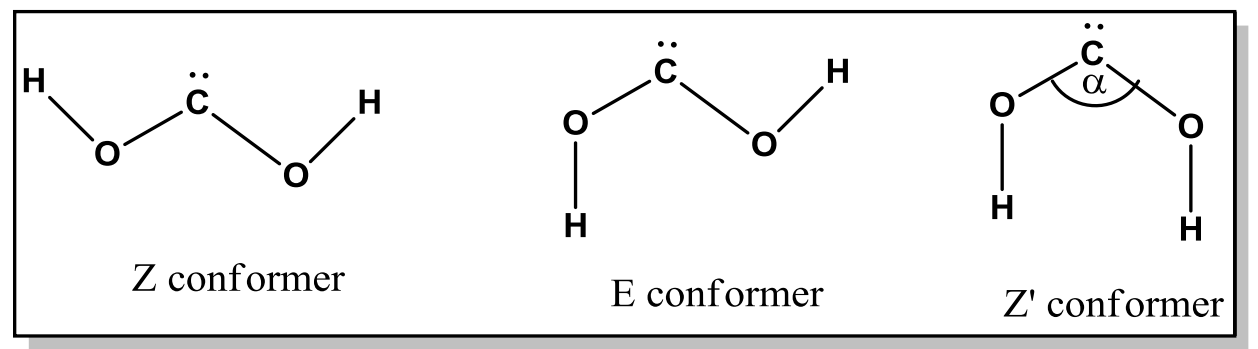

Fig. 6: Dihydroxycarbene under three conformations (Z, E, Z') 


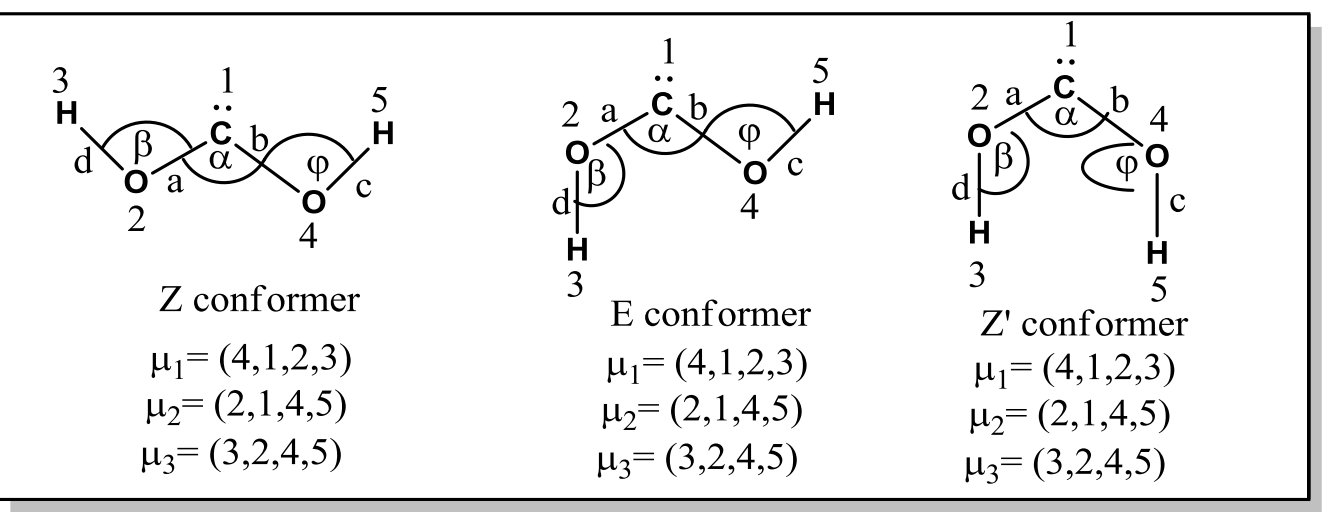

Fig. 7: Geometrical parameters of conformations Z, E and Z' of the dihydroxycarbene

Table 9: Geometrical parameters of the conformer E dihydroxycarbene after optimization of geometry in HF, MP2, B3LYP (cc-pVTZ) G3, CBS - Q, and CBS APNO.

\begin{tabular}{|c|c|c|c|c|c|c|c|c|c|c|}
\hline & & $\begin{array}{r}\text { E confo } \\
2\end{array}$ & $\begin{array}{l}\text { rmer for } \\
\mathrm{H}\end{array}$ & & & & & & & \\
\hline Methode & $\begin{array}{c}\mathrm{a}=\mathrm{O}_{2^{-}} \\
\mathrm{C}_{1}\end{array}$ & $\begin{array}{l}\mathrm{b}=\mathrm{C}_{1-} \\
\mathrm{O}_{4}\end{array}$ & $\begin{array}{l}\mathrm{C}=\mathrm{O}_{1^{-}} \\
\mathrm{H}_{5}\end{array}$ & $\mathrm{~d}=\mathrm{O}_{2}-\mathrm{H}_{3}$ & $\alpha$ & $\beta$ & $\varphi$ & $\mu 1$ & $\mu 2$ & $\mu 3$ \\
\hline $\mathrm{HF}^{\mathrm{a}} \mathrm{S}_{0}$ & 1,295 & 1,314 & 0,952 & 0,941 & 108,0 & 112,3 & 109,1 & 0,1 & $-180,0$ & $-179,9$ \\
\hline $\mathrm{MP2}^{\mathrm{a}} \mathrm{S}_{\mathrm{o}}$ & 1,326 & 1,326 & 0,963 & 0,963 & 104,7 & 105,1 & 105,1 & 180,0 & 180,0 & 0,1 \\
\hline G3 $S_{0}$ & 1,318 & 1,492 & 0,973 & 0,989 & 106,2 & 110,2 & 106,6 & 0,0 & $-180,0$ & 180 \\
\hline CBS-Q S & 1,314 & 1,314 & 0,966 & 0,983 & 106,4 & 110,6 & 107,2 & 0,0 & $-180,0$ & 180 \\
\hline $\begin{array}{l}\text { CBS-APNO } \\
\mathrm{S}_{0}\end{array}$ & 1,314 & 1,341 & 0,959 & 0,974 & 106,9 & 109,6 & 106,2 & 0,0 & -180 & 180 \\
\hline${\mathrm{B} 3 L Y P^{\mathrm{a}} \mathrm{S}_{0}}$ & 1,326 & 1,326 & 0,963 & 0,963 & 104,9 & 106,5 & 106,6 & $-180,0$ & $-180,0$ & 0,04 \\
\hline $\mathrm{HF}^{\mathrm{a}} \mathrm{T}_{1}$ & 1,337 & 1,338 & 0,945 & 0,945 & 123,4 & 111,1 & 111,1 & $-85,8$ & $-86,0$ & $-152,3$ \\
\hline $\mathrm{MP}^{\mathrm{a}} \mathrm{T}_{1}$ & - & - & - & - & - & - & - & - & - & - \\
\hline G3 $T_{1}$ & 1,359 & 1,359 & 0,977 & 0,977 & 124,3 & 109,2 & 109,2 & 85,8 & 85,8 & 154,4 \\
\hline CBS-QT $_{1}$ & 1,355 & 1,355 & 0,971 & 0,971 & 124,5 & 109,7 & 109,7 & 85,8 & 85,8 & 153,8 \\
\hline CBS-APNOT $_{1}$ & - & - & - & - & - & - & - & - & - & - \\
\hline $\mathrm{B} 3 \mathrm{LYP}^{\mathrm{a}} \mathrm{T}_{1}$ & 1,348 & 1,348 & 0,971 & 0,971 & 124,1 & 111,4 & 111,4 & $-102,2$ & 102,4 & \\
\hline
\end{tabular}

Lengths of linking in Angstroms, angles in degrees and $a=c c-p V Z T$ 
Table 10: Geometrical parameters of the conformer $Z$ dihydroxycarbene after optimization of geometry in HF, MP2, B3LYP (cc-pVTZ) G3, CBS - Q, and CBS APNO.

\begin{tabular}{|c|c|c|c|c|c|c|c|c|c|c|}
\hline & & Z conform & $\mathrm{r}$ for $2 \mathrm{OH}$ & & & & & & & \\
\hline Méthode & $\mathrm{a}=\mathrm{O}_{2}-\mathrm{C}_{1}$ & $\mathrm{~b}=\mathrm{C}_{1}-\mathrm{O}_{4}$ & $\mathrm{C}=\mathrm{O}_{1}-\mathrm{H}_{5}$ & $\mathrm{~d}=\mathrm{O}_{2}-\mathrm{H}_{3}$ & $\alpha$ & $\beta$ & $\varphi$ & $\mu 1$ & $\mu 2$ & $\mu 3$ \\
\hline $\mathrm{HF}^{\mathrm{a}} \mathrm{S}_{\mathrm{o}}$ & 1,302 & 1,302 & 0,941 & 0,941 & 106,1 & 108,5 & 108,5 & $-180,0$ & 180,0 & 0 \\
\hline $\mathrm{MP}^{\mathrm{a}} \mathrm{S}_{\mathrm{o}}$ & 1,326 & 1,326 & 0,963 & 0,963 & 104,7 & 105,1 & 105,1 & 179,9 & $-179,9$ & 0 \\
\hline G3 $S_{0}$ & 1,335 & 1,335 & 0,973 & 0,973 & 104,0 & 105,3 & 105,3 & 180,0 & 180,0 & 0 \\
\hline CBS-Q So & 1,330 & 1,330 & 0,966 & 0,966 & 104,3 & 105,7 & 105,7 & 180,0 & 180,0 & 0,0 \\
\hline CBS-APNO S。 & 1,327 & 1,327 & 0,956 & 0,956 & 104,8 & 105,0 & 105,0 & 180,0 & 180,0 & \\
\hline $\mathrm{B} \mathrm{LYP}^{\mathrm{a}} \mathrm{S}_{0}$ & 1,326 & 1,326 & 0,963 & 0,963 & 104,9 & 106,6 & 106,6 & $-180,0$ & 180,0 & 0 \\
\hline $\mathrm{HF}^{\mathrm{a}} \mathrm{T}_{1}$ & 1,338 & 1,338 & 0,944 & 0,944 & 123,4 & 111,6 & 111,6 & $-96,4$ & 96,4 & 0 \\
\hline $\mathrm{MP2}^{\mathrm{a}} \mathrm{T}_{1}$ & - & - & - & - & - & - & - & - & - & - \\
\hline G3 $T_{1}$ & 1,359 & 1,359 & 0,977 & 0,977 & 124,3 & 109,2 & 109,2 & 85,8 & 85,8 & 154,4 \\
\hline CBS-QT $_{1}$ & 1,355 & 1,355 & 0,971 & 0,971 & 124,5 & 109,7 & 109,7 & 85,8 & 85,8 & 153,8 \\
\hline $\begin{array}{l}\text { CBS- } \\
\text { APNOT }_{1}\end{array}$ & 1,355 & 1,355 & 0,964 & 0,964 & 124,2 & 108,3 & 108,3 & 88,7 & 88,7 & 160,2 \\
\hline $\mathrm{B}^{2} \mathrm{LYP}^{\mathrm{a}} \mathrm{T}_{1}$ & 1,348 & 1,348 & 0,971 & 0,971 & 124,1 & 111,4 & 111,4 & $-102,3$ & 102,3 & 0 \\
\hline
\end{tabular}

Lengths of linking in Angstroms, angles in degrees and a = cc - pVTZ

Table 11: Geometrical parameters of the conformer $Z^{\prime}$ of the dihydroxycarbene after geometry optimization in (HF, MP2, B3LYP (cc-pVTZ) G3, CBS - Q, and CBS APNO.)

\begin{tabular}{|l|c|c|c|c|c|c|c|c|c|c|}
\hline \multicolumn{10}{|c|}{ Z conformer for $2 \mathrm{OH}$} \\
\hline Méthode & $\mathrm{a}=\mathrm{O}_{2}-\mathrm{C}_{1}$ & $\mathrm{~b}=\mathrm{C}_{1}-\mathrm{O}_{4}$ & $\mathrm{c}=\mathrm{O}_{1}-\mathrm{H}_{5}$ & $\mathrm{~d}=\mathrm{O}_{2}-\mathrm{H}_{3}$ & $\alpha$ & $\beta$ & $\varphi$ & $\mu 1$ & $\mu 2$ & $\mu 3$ \\
\hline HF $^{\mathrm{a}} \mathrm{S}_{\circ}$ & 1,304 & 1,304 & 0,952 & 0,952 & 113,0 & 116,1 & 116,1 & 0,0 & 0,0 & 0 \\
\hline MP2 $^{\mathrm{a}} \mathrm{S}_{\circ}$ & 1,318 & 1,318 & 0,981 & 0,981 & 113,4 & 113,3 & 113,3 & $-0,1$ & 0,1 & 0 \\
\hline G3 $_{\circ}$ & 1,325 & 1,325 & 0,992 & 0,992 & 112,9 & 114,5 & 114,5 & 0 & 0 & 0 \\
\hline CBS-Q S $_{\circ}$ & 1,322 & 1,322 & 0,987 & 0,987 & 113,1 & 114,9 & 114,9 & 0 & 0 & 0 \\
\hline CBS-APNO So & & & & & & & & & & \\
\hline B3LYP $^{\mathrm{a}} \mathrm{S}_{\circ}$ & 1,313 & 1,313 & 0,987 & 0,987 & 113,9 & 114,6 & 114,6 & 0,0 & 0,0 & 0 \\
\hline \hline HF $^{\mathrm{a}} \mathrm{T}_{1}$ & 1,338 & 1,338 & 0,944 & 0,944 & 123,4 & 111,6 & 111,6 & $-96,4$ & 96,4 & 0 \\
\hline MP2 $^{\mathrm{a}} \mathrm{T}_{1}$ & & & & & & & & & & \\
\hline G3 T $_{1}$ & 1,359 & 1,359 & 0,977 & 0,977 & 124,2 & 109,9 & 109,9 & 98,0 & $-98,0$ & 0 \\
\hline CBS-QT $_{1}$ & 1,340 & 1,340 & 0,946 & 0,946 & 123,5 & 112,0 & 112,0 & 95,2 & $-95,2$ & 0 \\
\hline CBS-APNOT $_{1}$ & & & & & & & & & & \\
\hline B3LYP $^{\mathrm{a}} \mathrm{T}_{1}$ & 1,348 & 1,348 & 0,971 & 0,971 & 124,1 & 111,5 & 111,5 & 102,3 & $-102,3$ & 0 \\
\hline
\end{tabular}

Lengths of linking in Angstroms, angles in degrees and $a=c c-P v z t$ 
Am. J. Sci. Ind. Res., 2012, 3(3): 128-145

\section{CONCLUSION}

This geometry study of carbenes allows us to show that $-\mathrm{C}-\mathrm{H}$ bond in these molecules, is always longer in S0 state than in T1 state.

* If $\mathrm{X}=\mathrm{Cl}, \mathrm{C}-\mathrm{X}$ bond is always longer in S0 state than in T1 state.

* If $X=F, C-X$ bond is always longer in $T 1$ state than in S0 state.

-bond angle $\alpha=\mathrm{HCH}$ for methylene, and $\alpha=\mathrm{X}-\mathrm{C}-\mathrm{Y}$ for the monohalogenocarbenes and for the dihalogenocarbenes is always smaller in the S0 state than in T1 state. For the monohalogenocarbenes, bond angle increases in $\mathrm{Cl}$ to $\mathrm{F}$. This evolution is explained by the decrease of the electronegativity of the heteroatom and by the steric effects when their sizes increase.

-In the particular case of the monohydroxycarbene and the dihydroxycarbene, we have more complex geometry because of the presence of a dihedral angle. Monohydroxycarbene is plane in the SO state, and non-planar in T1 state with $\mathrm{C} 1$ symmetry.

-The dihydroxycarbene has three forms $Z, Z^{\prime}$ and $E$. Conformers Z, Z' and $E$ are plane in S0 state with $\mathrm{C}_{2} \mathrm{v}$ symmetry for $Z$ and $Z^{\prime}$ and $C$ s symmetry for $E$. In T1 state, we have two forms $Z$ and $Z$ ' because $E$ and $Z$ are identical geometrical parameters. $Z$ is nonplane (C2 symmetry), $Z^{\prime}$ is plane with C2v symmetry at the $\mathrm{S} 0$ state.

This work brings new insight into the structure of the studied carbenes.

\section{ACKNOWLEDGEMENTS}

The calculations were done using Gaussian 03 when one of us, KONE.M was staying in Trieste (Italy) at the laboratory of Molecular Modeling, Biostructural Nanomaterial and headed by Mr. Vladimir Freece in the group of ProfesSOr Stanislav Miertus in ICS (International Center for Science and High Technology) of UNIDO (United Nations Development Organization). We thank them for allowing the calculations of this publication.

Our acknowledge also to Ms BOCQUET N'GUESSAN Sylvie (59790 Ronchin France) for her help by revising the English version of this document.

\section{REFERENCES}

ADEOTI M.A. (1998). Doctorat de 3e cycle Université de COCODY

Alder R. W., Baker R., and Brown J. M. (1982). Mechanism in organic chemistry ,Wiley Interscience,( John Wiley \& SOns Ltd) N-Y, Ed. Page 146

Balázs H., Hue M.T. N., Tamás V., and Minh T. N. (2000). Chem. Phys, 2, 5042

BAUSCHLICHER Jr. C. W., SCHAEFER H. F., and BAGUS P. S. (1977). J. Am. Chem. S0c., 99, 71067110

Bondybey V. E. (1976). J. Mol. Spectrosc. 63-164

Cossi M. , and Barone V. (2000). J. Phys.Chem. 112-2427

Curtiss L. A., Raghavachari K., Redfern P. C., Rassolov V., and Pople J. A. (1998). J. Chem Phys. 109-7764

Dixon R. H. , and Simon J. (1970). J. Mol. Spectrosc. 36, 192.

Foresman J. B., Keith T. A., Wiberg K. B., Snoonian J., and Frisch M. J. (1996). J. Phys. Chem. 100-16098

Frisch Mr. J., Trucks G.W., Schlege H.B., Scuseria G.E., Mr Robb. A., Cheeseman J.R., Montgomery J.A., Jr., Vreven T., Kudin K. NR., Burant J.C., Mr. Millam J., lyengar S.S., Tomasi J., Baroness V., Mennucci B., Mr. Cossi, Scalmani G., Rega NR., Petersson G.A., Nakatsuji H., Hada Mr., Ehara Mr., Toyota K., Fukuda R., Hasegawa J., Ishida Mr., Nakajima T., Honda Y., Kitao O., Nakai H., Mr. Klene, Li X., Knox J.E., Hratchian H.P., Cross-country race J.B., Adamo C., Jaramillo J., Gomperts R., Stratmann R.E., Yazyev O., Austin A.J., Cammi R., Pomelli C., Ochterski J.W., Ayala P.Y., Morokuma K., Voth G.A., ElSalvador P., Dannenberg J.J., Zakrzewski V.G., Dapprich S., Daniels A.D., Strain Mr. C., Farkas O., Malick D.K., Rabuck A.D., Raghavachari K., Foresman J.B., Ortiz J.V., Cui Q., Baboul A.G., Clifford S., Cioslowski J., Stefanov B.B., Liu G., Liashenko A., Piskorz P., Komaromi I., Martin R.L., Fox D.J., Keith T., Al-Laham Mr. A., Peng C.Y., Nanayakkara A., Challacombe Mr., TOKEN ENTRY W. Gill, Johnson B., Chen W., Wong Mr. W., Gonzalez C., and Pople J.A., Gaussian, Inc., Pittsburgh Pa, 2003.

Goldfield D. and Simons J. (1981). J. Phys. Chem. 85, 569

Hastie J. W., Hauge R. H., and Margrave J. L. (1969). J. Mol. Spectrosc. 29-152

Hehre W.J., Radom L., Schleyer P.V.R., and Pople J.A. (1996). Ab initio Molecular Orbital Theory. Wiley, New York

Herzberg G. (1966). Molecular Spectra and Molecular Structure. III. Electronic Spectra and Electronic Structure of Polyatomic Molecules. Princeton NJ. Van Nostrand 
Herzberg G. (1972). Angew. Chem. 84-1126

Herzberg G., and Johns J. W. C. (1971). J. Chem. Phys. 54-2276

Herzberg G., and Mir M. (1974). The Spectra and Structures of Simple free Radicals.

Hohenberg P., Kohn W. (1964). Phys. Rev. 136, B 864

Irikura Karl K., W. A. Goddard, and J. L. Beauchamp. (1992). ,J. Amer. Chem. SOc. 114, 48

Ishiguro T., Hamada Y., and Tsubod M. (19 81). Bull. Chem. S0c. Japan. 54-367

Jacox M. E. , and Milligan D. E. (1967). J. Chem. Phys. 47, 1626

Jacox M. E. , and Milligan D. E. (1969). J. Chem. Phys. 50, 3252

Jacox M. E. , and Milligan D. E. (1970). J. Chem. Phys. 53, 2688

JENSEN P. , and BUNKER P. R.(1988). , J. Chem. Phys. 89,1327

Jensen P. , Bunker P. R. , and Hoy A. R. (1982). J. Chem. Phys. 77,5370

JOEL. F. L. , and JACK S. (1986). Molecular Structure and Energetics, JOEL. F. LIEBMAN and A. GREENBERG, Ed., VCH Publishers, (USA), Vol 1, Page 55.

Kakimoto M., Saito S. , and Hirota E. (1981). J. Mol. Spectrosc. 88, 300

Kakimoto M., Saito S. , and Hirota E. (1983). J. Mol. Spectrosc 90, 447;

Kakimoto M., Saito S. , and Hirota E. (1990). J. Mol. Spectrosc 97, 194

Kirchhoff W. H., Lide D. R., and Powell F. X. (1973). J. Mol. Spectrosc. 47-491

Knowless P. J. Schutz M. , and Wemer H.J. (2000). Ab initio methods for electron correlation in molecules in Modern. Method and algorithms of quantum chemistry, volume 1, Publication series of the John Von Neumann institute for computing (NIC)

Kohn W., L. J. Sham. (1965).Phys. Rev. 140, A1133
Maltsev A. K., Mikaelian R. G. , and Nefedov O. M. (1971). Dokl. Akod. Nauk SSSR. 201-901

Maltsev A. K., Mikaelian R. G., and Nefedov O. M. (1971). Izv. Akod. Nauk SSSR. Ser. Rhim. 199

Maltsev A. K., Mikaelian R. G., and Nefedov O. M. (1971). Proc. Nat. Acad. Sci. USA. 68-3238

Mathews C. W. (1966). J. Chem. Phys. 45-1068

Mathews C. W. (1967). Can. J. phys. 45-2355

Merer A. J. , and Travis D.N. (1966). Can. J. Phys. 44, 5251541

Milligan D. E. , and Jacox M. E. (1967). J. Chem. Phys. 47703

NEF J.U. (1897). Ann. , 202-298

Powell F. X., and Lide D. R. (1966). J. Chem. Phys. 451067

Roothaan C.C.J.(1951). Rev. Mod. Phys. 23-69

Samsonov Y. N. , and Petrov A. K. (1981). Chem. Phys. Lett. 84, 183

Sears T. Y., Bunker P. R., McKellar A. R. W., and al. (1 980). J. Chem. Phys. 77, 5348-5370

Shultz G., Tremmel J., Hargittai I., and al. (1979). J. Mol. Struct. 55, 207

Shultz G., Tremmel J., Hargittai I., and al. (1982).J. Mol. Struct. 82, 107

Szabo .A., Ostlung N. S. (1989). Modern Quantum Chemistry, Mc Graw-Hill Publishing Company, New York,

Uy O.M., Muenov D. M. , and Margrave J. L. (1969). Trans. Paraday S0c. 65-1296

Vaida. E. (1976). J. Organometall. Chem. 33-105

WASSERMAN E.,. KUCK V. J, HUSTON R. S., ANDERSON E. D., YAGER. W. A. J. (1971). , Chem. Phys., 54, 4120

Zitte1 P. F., ElliS0n G. B., O'Nei1 S.V. , and al. (1976). J. Amer. Chem. S0c. 98-3731 